\title{
Crustal deformation around the northern and central Itoigawa-Shizuoka Tectonic Line
}

\author{
Takeshi Sagiya ${ }^{1}$, Takuya Nishimura ${ }^{1}$, Yoshihisa Iio ${ }^{2}$, and Takashi Tada ${ }^{1}$ \\ ${ }^{1}$ Geographical Survey Institute, 1 Kitasato, Tsukuba, Ibaraki 305-0811, Japan \\ ${ }^{2}$ Earthquake Research Institute, University of Tokyo, 1-1-1 Yayoi, Bunkyo-ku, Tokyo 113-0032, Japan
}

(Received January 11, 2002; Revised August 11, 2002; Accepted August 12, 2002)

\begin{abstract}
We established a dense permanent GPS array around the northern and central Itoigawa-Shizuoka Tectonic Line (ISTL) in order to study loading processes of inland active faults. 1-4 years observation has revealed concentrated deformation (about $0.3 \mathrm{ppm} / \mathrm{yr}$ ) around the East Matsumoto-Basin Fault, an active fault along the ISTL, consistent with historic triangulation data. The deformation pattern is explained by dislocation models incorporating horizontal detachment fault with steady slip in the upper crust. However, deformation data alone cannot determine the model and there exist different possibilities. The vicinity of the Gofukuji fault is being deformed less in spite of the large long-term slip rate. These observations indicate that the deformation pattern is laterally heterogeneous along the ISTL. The two faults are considered to be loaded by different mechanisms.
\end{abstract}

\section{Introduction}

Large earthquakes frequently occur in the Japanese inland areas, causing severe loss of human life as in the case of the 1995 Kobe earthquake. However, the nature of inland earthquakes is not well understood. In particular, the generation mechanism of inland earthquakes is an important problem for seismologists and geophysicists to solve.

In order to understand the whole physical process related to inland earthquakes, we need a comprehensive understanding of the accumulation and release processes of tectonic stress and strain. Crustal deformation around active faults, which presumably become source regions of future earthquakes, provides an essential constraint on the loading process.

In the Japanese islands, the Geographical Survey Institute has been operating a dense permanent GPS array called GEONET since 1994 (e.g. Sagiya et al., 2000). GEONET has revealed the spatial distribution of crustal strain and its temporal changes with high accuracy, which is fundamental information in studying inland earthquakes. However, the average spacing of the GEONET sites is about $25 \mathrm{~km}$, being comparable to a typical source size of a magnitude 7 earthquake. In order to study deformation related to inland earthquakes, investigation of more detailed deformation pattern is necessary.

We established a dense GPS array around the northern and central portion of the Itoigawa-Shizuoka Tectonic Line (hereafter called ISTL), which is one of the major active faults in the Japanese islands (Fig. 1). In this paper, we describe preliminary results of GPS observation and discuss their implications for the generation mechanism of inland earthquakes.

\section{Itoigawa-Shizuoka Tectonic Line}

The Itoigawa-Shizuoka Tectonic Line is a major geological structure dividing the Japanese mainland into northeastern and southwestern parts (Fig. 1). Northern and central parts of the ISTL are considered to be an active fault zone while the southern ISTL has ceased its activity (e.g. Okumura et al., 1998). The Matsumoto Basin west of the northern ISTL is filled with thick ( $>6 \mathrm{~km}$ ) Quaternary sediments (Ikami et al., 1986).

According to geomorphological as well as geological studies, the slip rate of the Gofukuji Fault in the central ISTL is estimated as large as $8.6-9.5 \mathrm{~mm} / \mathrm{yr}$ with an average earthquake repeat time of about 1,000 years (Ikeda and Yonekura, 1986; Okumura et al., 1994). The East Matsumoto-Basin Fault (hereafter called EMBF) in the northern ISTL is also active, having $3.0 \mathrm{~mm} / \mathrm{yr}$ slip rate (Okumura et al., 1998). In spite of such large slip rates, no earthquake of magnitude 7 or larger is known to have occurred in this region for more than 1,000 years. Therefore the Gofukuji Fault is now considered to have one of the highest probabilities of earthquake occurrence as an inland active fault in Japan.

To the east of the EMBF, there is an area of prominent folding of Miocene formations, which is called the Minochi Belt or the Saigawa Disturbance Zone (hereafter called as SDZ) (Kato and Sato, 1983). There is no evidence that this fold belt is presently active. However, as will be demonstrated later, it is evident that present deformation is concentrated around this fold belt, implying active folding. The relation between the active folding of the SDZ and the faulting activity of the EMBF is one of the important targets of this study. 


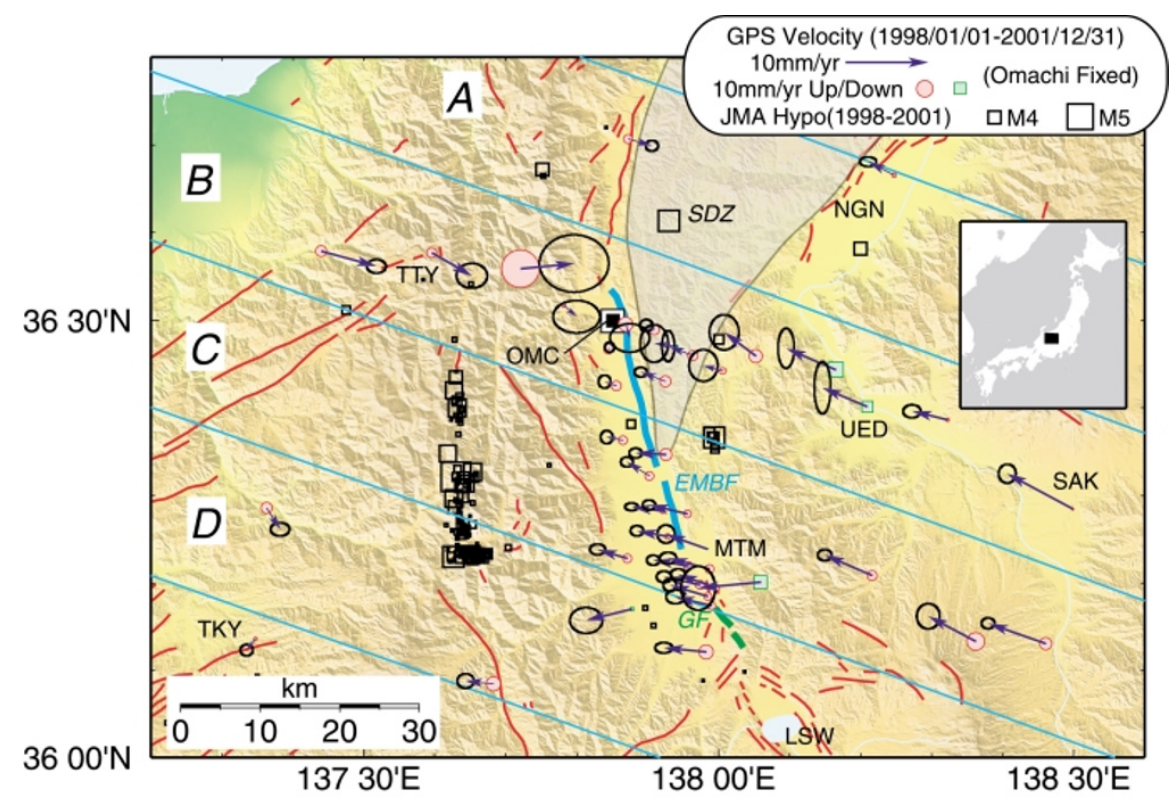

Fig. 1. Crustal deformation rate around the northern and central ISTL estimated from continuous GPS observation from January 1998 to December 2001. Inset map shows the location of this area. GPS station at Omachi (OMC) is assumed to be fixed (denoted by double square). Open squares denote epicenters of shallow (depth $<30 \mathrm{~km}$ ) earthquakes during 1998-2001 by Japan Meteorological Agency. Shaded area (SDZ) denotes the Saikawa Disturbance Zone. Red lines show active faults. East Matsumoto Basin Fault (EMBF) and Gofukuji Fault (GF) are highlighted by different colors. MTM: Matsumoto, NGN: Nagano, UED: Ueda, TTY: Tateyama, TKY: Takayama, LSW: Lake Suwa.

\section{Crustal Deformation around the Northern and Central ISTL}

\subsection{Triangulation data}

A triangulation revision survey was conducted around the northern ISTL in 1985-1989, and crustal deformation for about 85 years was revealed (Tada and Hashimoto, 1990; Sagiya and Tada, 1998). The survey was conducted for a dense triangulation network with $8-10 \mathrm{~km}$ spacing. We find significant accumulation of crustal strain along the northern ISTL (Fig. 2). In particular, the eastern side of the EMBF between Omachi (OMC) and Matsumoto (MTM) shows large (30-50 ppm) compressive strain in WNW-ESE direction. There was the 1918 Omachi earthquake (M6.5) near OMC, which might result in significant deformation, but a recent study of a fault model for the Omachi earthquake does not account for the large strain (Sagiya, 2002). Since there was not any other earthquake larger than magnitude 6.5 during the time period, there must be a steady deformation process. Concentration of large strain in a narrow zone implies that the deformation may be associated with faulting along the EMBF as well as folding of the SDZ. On the other hand, it is worthwhile to point out that the measurements around the Gofukuji Fault area, southeast of MTM, shows small strain accumulation.

\subsection{GPS array and processing}

In addition to the original GEONET stations, the Science and Technology Agency (presently the Ministry of Education, Culture, Sports, Science and Technology, abbreviated as MEXT) installed 16 permanent GPS sites (hereafter called MEXT sites) in our study area in 1997. However, these 16 stations are mostly distributed right along the ISTL and the GPS array was not suitable for investigating the loading process of the fault.

Therefore we newly installed 11 permanent GPS sites around the northern and central ISTL in 1999 and 2000 in order to complement the existing GPS array. The newly installed permanent GPS sites are intended to align across the ISTL near OMC in the direction of N70W, approximately parallel to the maximum compressive strain/stress direction in this area (Tada and Hashimoto, 1990; Tsukahara and Kobayashi, 1991). The spatial interval of the new GPS sites is as short as 2 to $10 \mathrm{~km}$ so that a detailed deformation profile can be obtained.

We process GPS phase data with the Bernese GPS software version 4.2 (Hugentobler et al., 2001), using IGS precise ephemerides of GPS satellites. Baseline-wise ambiguity resolution was carried out and daily station coordinates were calculated by solving all the normal equations simultaneously.

There was no large earthquake in the study area during the period 1998-2001 except for swarm activity in the mountain area in the summer of 1998 (Fig. 1). Time series data of each coordinate component basically show a linear trend with some seasonal signals. We estimate station velocities by fitting a straight line plus an annual sinusoidal curve to each coordinate time series. The estimated velocity vectors of all the GPS sites are shown in Fig. 1. Error ellipses in Fig. 1 show $95 \%$ confidence level calculated based on Mao et al. (1999) taking white noise as well as flicker noise components into account.

\subsection{GPS results}

We can clearly see that the horizontal velocity vectors in zone $\mathrm{B}$ are directed toward $\mathrm{OMC}$ in Fig. 1, implying compressive deformation in the WNW-ESE direction. In zone $\mathrm{B}$, the deformation is almost 2-dimensional and the velocity components in the $\mathrm{N} 20 \mathrm{E}$ direction are small and mostly less than $\pm 2 \mathrm{~mm} / \mathrm{yr}$. Such a deformation pattern becomes apparent in the velocity profile in the N110E direction (Fig. 3). 


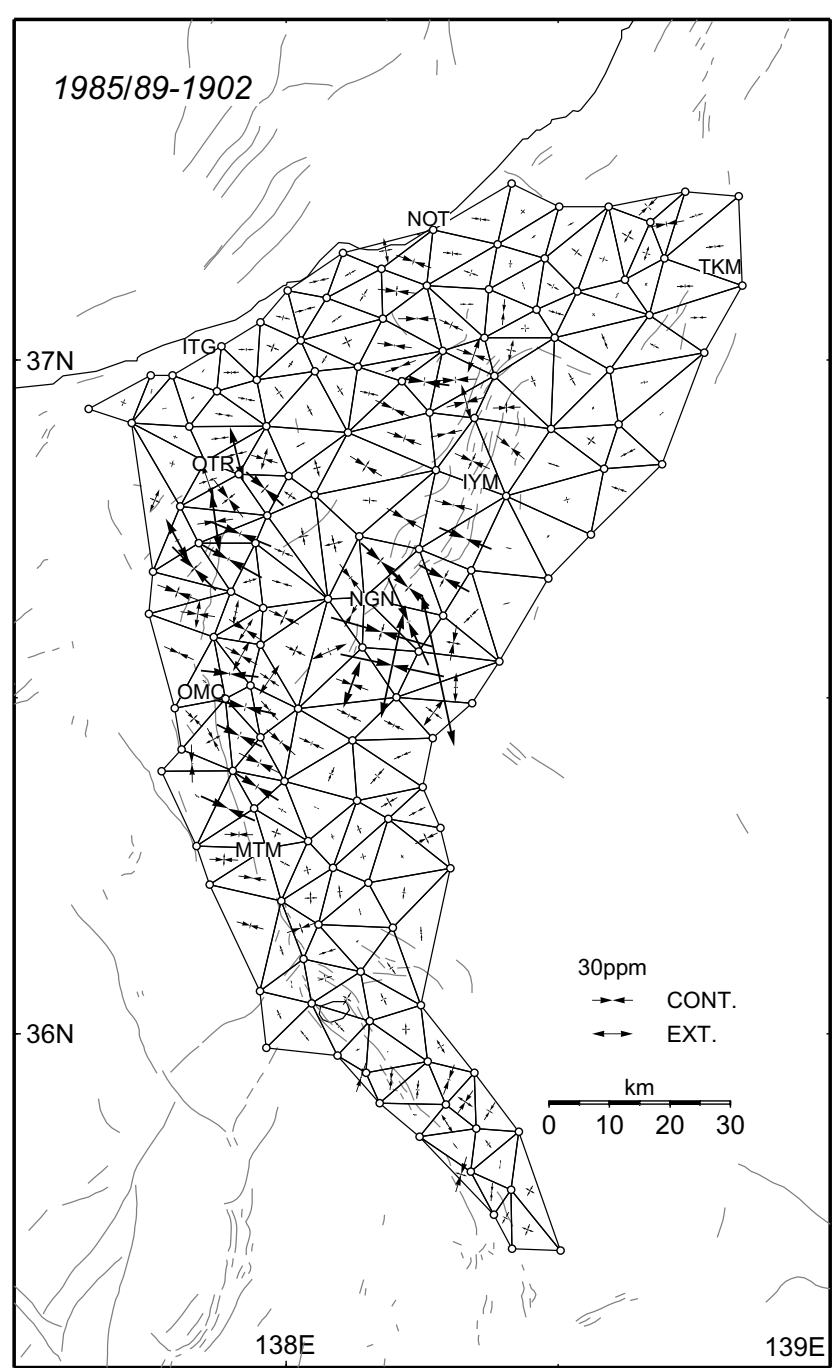

Fig. 2. Horizontal crustal strain in the northern and central ISTL estimated from triangulation (Sagiya and Tada, 1998). Thin lines denote surface trace of active faults. Large strain southeast of Nagano (NGN) was caused by the Matsushiro seismic swarm activity in 1960's.

In Fig. 3, we can identify concentrated deformation of zone $\mathrm{B}$ near OMC. The EMBF crosses zone $\mathrm{B}$ near the distance of $0 \mathrm{~km}$. Although there is still some uncertainties in the velocity profile, we can conclude that deformation is concentrated within a narrow zone $( \pm 15 \mathrm{~km}$ from OMC) along the profile. Linear strain rate along the profile line is estimated to be about $0.3 \mathrm{ppm} / \mathrm{yr}$ in this deformation zone. This result is not only qualitatively but also quantitatively consistent with the 1902-1985/89 triangulation data (Fig. 2), implying steadiness of the deformation. Strain rate outside this area is much smaller, less than $0.1 \mathrm{ppm} / \mathrm{yr}$. Thus the area around $\mathrm{OMC}$ is recognized as a concentrated deformation area. This deformation zone is a part of the Niigata-Kobe Tectonic Zone proposed by Sagiya et al. (2000).

An important characteristic of the deformation pattern is that the direction of maximum compression is oblique to the surface trace of the EMBF. This probably indicates that the EMBF is an oblique fault, including significant left-lateral strike slip. Another interesting thing is that the velocity profile in zone $\mathrm{C}$ looks almost the same as that of zone B although there are not enough data in the western side. The
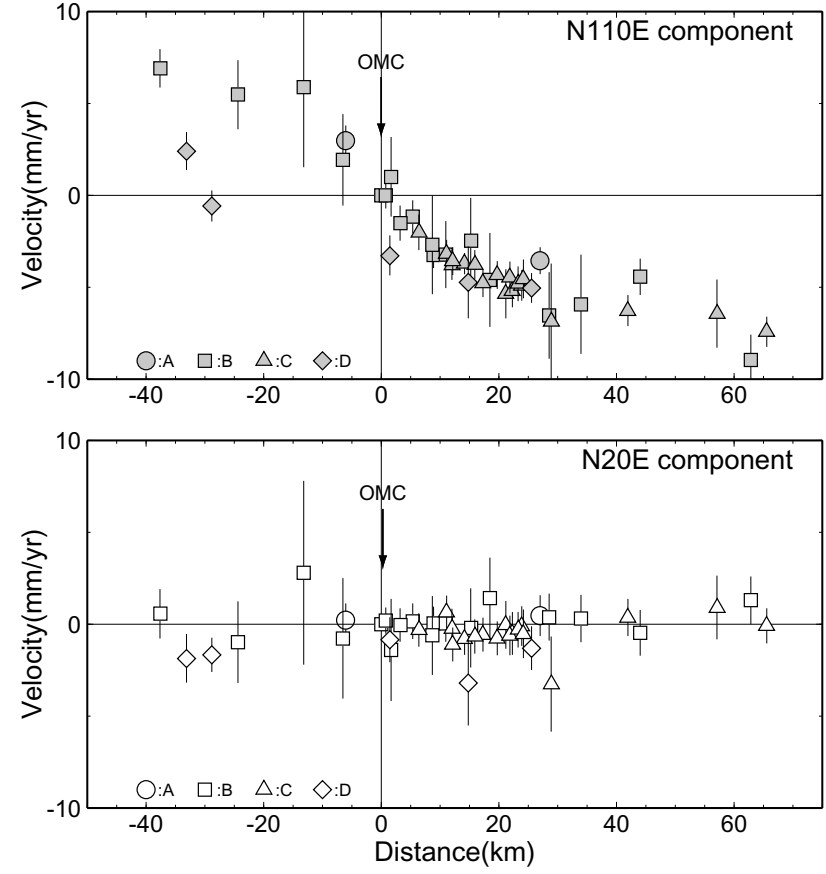

Fig. 3. GPS velocity profile around the northern and central ISTL. (top) velocity component in $\mathrm{N} 110 \mathrm{E}$ direction plotted along the same direction. (bottom) velocity component in N20E direction plotted along the N110E direction. A-D corresponds to the four parallel zones shown in Fig. 1.

surface trace of the EMBF is situated between $10-30 \mathrm{~km}$ in zone $\mathrm{C}$ where deformation is not so large. This indicates there is a significant lateral variation in the deformation pattern along the EMBF.

In contrast to the deformation near $\mathrm{OMC}$, the deformation pattern around the Gofukuji Fault changes more gradually, with much smaller strain rate. This appears to contradict the larger long-term slip rate of Gofukuji Fault. We discuss this paradox later.

The study area is located roughly $200 \mathrm{~km}$ north of the Suruga Trough and $300 \mathrm{~km}$ west of the Japan Trench. Because of this large distance from major plate boundaries and localized deformation signals within this area, direct effects of plate subduction, such as interplate locking, are not significant. However, the Japanese islands as a whole are located within a plate boundary region, and the plate subduction must be one of the major driving forces to cause such inland deformation indirectly.

\subsection{Preliminary slip model}

We developed a preliminary model calculation based on the deformation profile B in Fig. 3. The concentrated deformation around the EMBF places an important constraint on the loading process of the fault. One possible model of compressive deformation is a collision model (Shimazaki and Zhao, 2000), which is mathematically identical to the horizontal detachment model (Hirahara et al., 1998). Because the deformation near OMC is concentrated in a narrow area, we need to extend the detachment fault to shallower depth in the upper crust.

We conducted a 2-dimensional calculation of surface deformation with the elastic half-space model assuming the EMBF to be dipping eastward based on structural explo- 

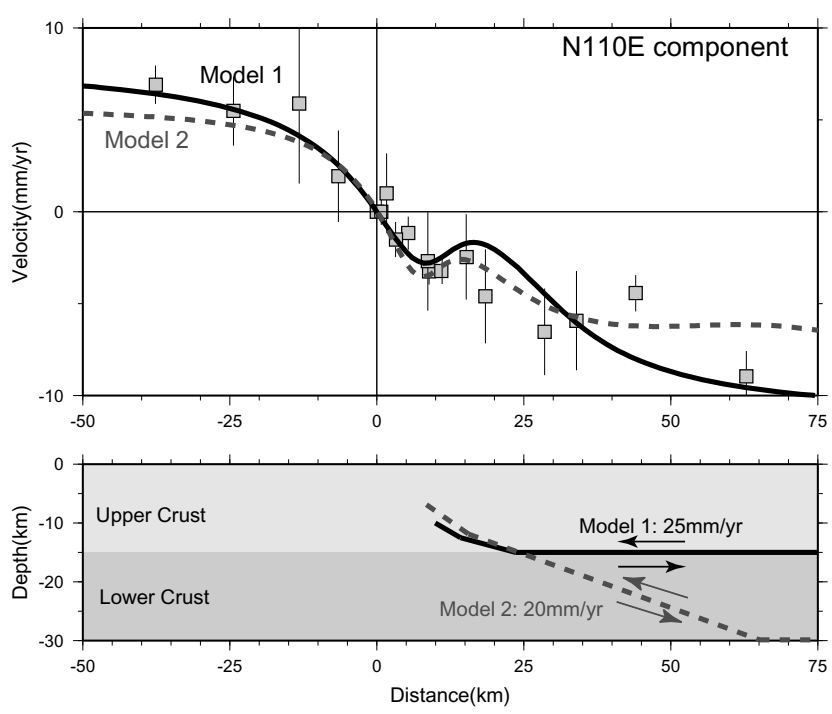

Fig. 4. Comparison of dislocation models for GPS velocity profile in zone B of Fig. 1. Calculated velocity patterns refer GPS site at Omachi.

ration data (Okubo et al., 2000). Among various candidate models, we show two cases in Fig. 4. Model 1 assumes a horizontal detachment fault at the depth of $15 \mathrm{~km}$. This model implies that lateral shortening occurs only in the upper crust and the stress in the lower crust is relaxed because of its low viscosity. Since there has been no large earthquake rupturing the whole upper crust for more than 1,000 years, any localized deformation associated with the fault must have already spread out if the characteristic relaxation time of the lower crust is less than 100 years. On the other hand, Model 2 assumes that a deeper extension of the fault extends into the lower crust until $30 \mathrm{~km}$ depth where a detachment fault is located. Model 2 implies the lower crust has a much larger viscosity and deformation in the lower crust concentrates on the fault zone.

Deformation profiles calculated from the two models are compared with the observation in the upper plot of Fig. 4. Both models can reproduce the observed deformation pattern well and it is difficult to decide which model is better. In addition, the Matsumoto Basin is filled with thick sediments and we need to take the laterally heterogeneous structure into account for more realistic modeling of deformation. Thus the structural information, distribution of elastic property and fault configuration, are definitely needed.

Although we cannot distinguish the two models and there may be still other candidates, we infer that such steady slip causes the significant surface deformation as revealed by the GPS observation. Also, it is highly probable that such a steady fault motion drives the folding process in the SDZ. Part of the compressive strain may be released by such plastic deformation. It is important to resolve how much strain energy is being released by plastic deformation in order to estimate the accumulated elastic strain energy correctly. The smaller estimates of long-term slip rate of the EMBF than that of the Gofukuji Fault may be associated with the strain release in the SDZ.

\section{Discussion}

The smaller strain rate around the Gofukuji Fault compared with the EMBF may seem paradoxical. However, if we look at the GPS-derived deformation pattern carefully, we notice that similar deformation extends to a much wider area around the Gofukuji Fault, in contrast to the narrow deformation zone around the EMBF. This indicates that strain energy associated with the faulting of the Gofukuji Fault may be distributed in a wider area extending about $50 \mathrm{~km}$ to the both sides of the fault. Relative displacement rate between the two GPS sites at the both ends of this wide area is comparable to the long-term slip rate of the Gofukuji Fault. Shear strain seems almost equally distributed in this wide area. As an explanation for such broadly distributed strain, the lower crust and the upper mantle below the Gofukuji Fault may have been completely relaxed because of the absence of large earthquakes for more than 1,000 years. This may provide a constraint on the rhological property of the lower crust in this area. If there is a steady slip on the deeper extension of the fault, deformation would localize near the surface trace as in the case of the EMBF. So we can exclude a possibility of such a steady slip occurring beneath the Gofukuji Fault. Thus the present loading mechanism of the EMBF and the Gofukuji Fault may be quite different. Detailed structural study of this area and realistic modeling efforts will be necessary to better understand the loading process of this area.

Acknowledgments. Authors express their sincere thanks to G. C. Beroza and R. Burgman for their critical reviews. K. Iwata, R. Kagawa, S. Nemoto and M. Tsuzuku of Geographical Survey Institute are greatly acknowledged for their support in construction and operation of GPS sites. One of the authors, T. Tada, passed away on February 17, 2002. Other authors express sincere condolence and would like to praise his great contributions to crustal deformation study. This study was conducted as a part of the "Comprehensive Research on Slip and Flow Processes in and below the Seismogenic Region" supported by the Special Coordination Fund of the Ministry of Education, Culture, Sports, Science and Technology (MEXT)

\section{References}

Hirahra, K., M. Ando, Y. Hoso, Y. Wada, and T. Nakano, Following fault motions by GPS observation, Earth Monthly, 20, 149-153, 1998 (in Japanese).

Hugentobler, U., S. Schaer, and P. Fridez (ed.), Documentation of the Bernese GPS software version 4.2, 515 pp., 2001.

Ikami, A., T. Yoshii, S. Kubota, Y. Sasaki, A. Hasemi, T. Moriya, H. Miyamachi, R. S. Matsu'ura, and K. Wada, A seismic-refraction profile in and around Nagano prefecture, central Japan, J. Phys. Earth, 34, 457 474, 1986.

Ikeda, Y. and N. Yonekura, Determination of late Quaternary rates of net slip on two major fault zones in central Japan, Bull. Dept. Geogr. Univ. Tokyo, 18, 49-63, 1986.

Kato, K. and T. Sato, Geology of the Shinano-Ikeda region, Report of regional geological studies (with 1:50000 map), Geological Survey of Japan, 93 pp., 1983.

Mao, A., C. G. A. Harrison, and T. Dixon, Noise in GPS coordinate time series, J. Geophys. Res., 104, 2797-2816, 1999.

Okubo, S., Y. Ikeda, T. Kumamoto, G. Seta, N. Matsuta, H. Chiba, and Y. Arai, 2-D and 3-D subsurface density structure in the northern part of the Itoigawa-Shizuoka Tectonoic Line derived by gravity surveying, J. Geod. Soc. Japan, 46, 177-186, 2000.

Okumura, K., K. Shimokawa, H. Yamazaki, and E. Tsukuda, Recent surface faulting events along the middle section of the Itoigawa-Shizuoka Tectonic Line - trenching survey of the Gofukuji Fault near Matsumoto, central Japan-, Zisin, 46, 425-438, 1994 (in Japanese with English abstract). 
Okumura, K., R. Imura, T. Imaizumi, M. Togo, H. Sawa, K. Mizuno, and Y. Kariya, Recent surface faulting events along the northern part of the Itoigawa-Shizuoka Tectonic Line-Trenching survey of the Kamishiro Fault and East Matsumoto Basin Faults, central Japan-, Zisin, 50 suppl., 35-51, 1998 (in Japanese with English abstract).

Sagiya, T., Yet another fault model for the 1918 Omachi earthquakeimplications for Itoigawa-Shizuoka Tectonic Line Fault Zone-, Zisin, 2002 (submitted).

Sagiya, T. and T. Tada, Crustal deformation and tectonics of the eastern margin of Japan Sea, Earth Monthly, 20, 515-521, 1998 (in Japanese).

Sagiya, T., S. Miyazaki, and T. Tada, Continuous GPS array and present-day crustal deformation of Japan, PAGEOPH, 157, 2303-2322, 2000.
Shimazaki, K. and Y. Zhao, Dislocation model for strain accumulation in a plate collision zone, Earth Planets Space, 52, 1091-1094, 2000.

Tada, T. and M. Hashimoto, Horizontal crustal deformation in the northern and central Fossa Magna regions and its tectonic significance, Chigaku Zasshi, 99, 92-97, 1990 (in Japanese with English abstract).

Tsukuhara, H. and Y. Kobayashi, Crustal stress in the central and western parts of Honshu, Japan, Zisin, 44, 221-231, 1991 (in Japanese with English abstract).

T. Sagiya (e-mail: sagiya@gsi.go.jp), T. Nishimura, Y. Iio, and T. Tada 